\title{
Correct Scoring of Hypopneas in Obstructive Sleep Apnea Reduces Cardiovascular Morbidity
}

\author{
James M. Parish, $M D^{1}$ \\ David Baratz, MD2 \\ ${ }^{1}$ Mayo Clinic Arizona; Phoenix, AZ \\ ${ }^{2}$ Pulmonary Associates, Phoenix, AZ;
}

Obstructive Sleep Apnea (OSA) is a life-altering disease with a prevalence of $10 \%$ in men and $9 \%$ in women (1). In some groups (severe obesity, BMl > $40 \mathrm{~kg} / \mathrm{m} 2$ ) the prevalence may be as high as $40 \%$ (2). One of the most controversial areas in the field of sleep medicine for many years has been the definition of the syndrome. Investigators who first identified OSA created the apnea index (AI), the number of apnea events per hour. An apnea was defined as a complete cessation of airflow for at least 10 seconds. When continuous positive airway pressure (CPAP) treatment for OSA was first introduced, a definition that third-party payors, such as the Center for Medicare and Medicaid Services (CMS), could use to determine which patients qualified for treatment was needed. The definition at that time was 30 apnea events during a 6-hour recording, which corresponded to an Al of 5 events per hour. As further information developed about the syndrome of OSA, the presence of the hypopnea was recognized. A hypopnea was an event that was not a complete cessation of airflow, but rather was a reduction in airflow associated with either a reduction of oxygen saturation and/or an arousal from sleep. Hypopneas were found to have the same clinical significance as apneas. However, controversy surrounded the exact definition of hypopnea. What percentage reduction in airflow? What degree of desaturation, $3 \%, 4 \%$, other? (3) And what was the exact definition of arousal? Additionally, at this time, CMS would not recognize the use of hypopneas in the definition of OSA for the purpose of qualifying patients for the use of CPAP and a result, many patients with predominantly hypopneas did not meet the qualifications for CPAP.

Subsequently, an agreement between the sleep community and CMS was reached utilizing the definition of hypopnea of a reduction of airflow to $30 \%$ of baseline and a $4 \%$ oxygen desaturation (4). This definition was based on findings from the Sleep Heart Health Study demonstrating significant cardiovascular effects in patients with obstructive sleep apnea/hypopnea syndrome utilizing this definition. The association of hypopnea with arousal was left out of this definition at this time because there was poor reproducibility in scoring. While the benefit of this agreement was the inclusion of hypopneas which allowed more patients to qualify for PAP therapy, there was a large group of individuals with hypopneas with $3 \%$ desaturation and/or an arousal who did not meet the criteria for therapy.

In 2012 the American Academy of Sleep Medicine (AASM) recommended that the hypopnea definition include any decrease in airflow by at least $30 \%$ from the baseline with an oxygen desaturation of at least $3 \%$ or an arousal from sleep $(5,6)$. This definition 
often forced many sleep laboratories to score studies twice, once using the $3 \%$ rule and the other using the $4 \%$ rule. The $3 \%-4 \%$ controversy has continued for many years.

Since then CMS and other payors has not adopted the recommendation of the AASM primarily because of lack of evidence that a $3 \%$ decrease is associated with cardiovascular disease and relied on a more restrictive definition of OSA fewer patients with OSA (as defined by the AASM) have been able to obtain life changing therapy such as CPAP. In the view of many, this has increased the risk of developing cardiovascular disease.

In this issue of SWJPCC an article by Quan et al., "The Association Between Obstructive Sleep Apnea Defined by 3 Percent Oxygen Desaturation or Arousal Definition and Self-Reported Cardiovascular Disease in the Sleep Heart Health Study" demonstrates that employing a definition of hypopnea utilizing a $3 \%$ reduction in the oxygen desaturation results in an equivalent incidence of cardiovascular disease (CVD) or coronary heart disease (CHD) as the more restrictive $4 \%$ definition (7). The shows that in patients followed in the Sleep Heart Health Study (SHHS) that 6307 participants developed $\mathrm{CVD} / \mathrm{CHD}$ at equal rates based on odds ratios and $95 \%$ confidence intervals. The SHHS was a prospective multicenter cohort study designed to investigate the relationship between OSA and CVD (8). 6441 subjects 40 years and older were recruited in 1995 to undergo polysomnography, having demographic information taken and then self-report if they were ever told by a doctor that they had angina, heart attack, heart failure, stroke or undergone coronary bypass surgery or coronary angioplasty. CHD or CVD was defined as a positive response to one or more of these conditions or procedures. In addition, the presence of hypertension, diabetes, depression, insomnia and hypersomnia in these subjects was assessed.

In this current analysis of the SHHS 3326 participants were found not to have OSA by the $4 \%$ CMS rule. Using the 3\% AASM definition of hypopnea, 2247 of the 3326 participants were found to have OSA. Participants that were not diagnosed by the $4 \%$ rule had OSA ranging in the mild to severe categories. This study suggests that the regulatory requirement by the CMS of using a $4 \%$ decrease in oxygen desaturation denies a substantial number of patients the opportunity for treatment of their OSA and may worsen cardiovascular disease or coronary heart disease.

This paper is the first to assess the association of the $3 \%$ criteria in the risk of developing CVD/CHD in patients with OSA. The importance of this paper cannot be underestimated. There are no other studies that have been done or are being done that investigate the risk between OSA or cardiovascular disease using polysomnographic measurements. By utilizing the $3 \%$ rule in clinical practice a much larger number of patients would meet the diagnostic criteria of OSA and be eligible to receive treatment. Treatment of OSA with CPAP has been shown to reduce the severity of CVD, CHD, diabetes, motor vehicle accidents. It also improves daytime alertness, concentration, emotional stability, reduces snoring, and reduces medical expenses (9-11).

The current study provides the necessary information to help resolve the ongoing controversy. The studies data is very robust, using the well-known Sleep Heart Health 
study. A limitation of the study is that it relies on self-reported history of cardiovascular disease, which is subject to recall bias, but the data is otherwise very strong and robust. Also, some of the correlations are less statistically significant when adjusted for other co-variates.

This study provides proof that a large number of patients with symptomatic and dangerous OSA have been undertreated. It calls for a change in the policy by the CMS and all other payors to provide therapy for patients with OSA based on the American Academy of Sleep Medicine criteria using a 3\% reduction in oxygen saturation to score hypopneas.

\section{References}

1. Peppard PE, Young T, Barnet JH, Palta M, Hagen EW, Hla KM. Increased prevalence of sleep-disordered breathing in adults. Am J Epidemiol. 2013 May 1;177(9):1006-14. [CrossRef] [PubMed]

2. Rajala R, Partinen M, Sane T, Pelkonen R, Huikuri K, Seppäläinen AM. Obstructive sleep apnoea syndrome in morbidly obese patients. J Intern Med. 1991 Aug;230(2):125-9. [CrossRef] [PubMed]

3. Redline S, Sanders M. Hypopnea, a floating metric: implications for prevalence, morbidity estimates, and case finding. Sleep. 1997 Dec;20(12):1209-17. [CrossRef] [PubMed]

4. Meoli AL, Casey KR, Clark RW, Coleman JA Jr, Fayle RW, Troell RJ, Iber C; Clinical Practice Review Committee. Hypopnea in sleep-disordered breathing in adults. Sleep. 2001 Jun 15;24(4):469-70. [PubMed]

5. Anonymous. CPAP for Obstructive Sleep Apnea Updated 2020. https://www.cms.gov/Medicare/Coverage/Coverage-with-EvidenceDevelopment/CPAP.

6. Berry RB, Budhiraja R, Gottlieb DJ, Gozal D, Iber C, Kapur VK, Marcus CL, Mehra R, Parthasarathy S, Quan SF, Redline S, Strohl KP, Davidson Ward SL, Tangredi MM; American Academy of Sleep Medicine. Rules for scoring respiratory events in sleep: update of the 2007 AASM Manual for the Scoring of Sleep and Associated Events. Deliberations of the Sleep Apnea Definitions Task Force of the American Academy of Sleep Medicine. J Clin Sleep Med. 2012 Oct 15;8(5):597-619. [CrossRef] PMID: [PubMed]

7. Quan SF, Budhiraja R, Javaheri S, Parthasarathy S, Berry RB. The Association Between Obstructive Sleep Apnea Defined by 3 Percent Oxygen Desaturation or Arousal Definition and Self-Reported Cardiovascular Disease in the Sleep Heart Health Study. Southwest J Pulm Crit Care. 2020;21(4):86-103. [PubMed]

8. Quan SF, Howard BV, Iber C, Kiley JP, Nieto FJ, O'Connor GT, Rapoport DM, Redline S, Robbins J, Samet JM, Wahl PW. The Sleep Heart Health Study: design, rationale, and methods. Sleep. 1997 Dec;20(12):1077-85. [PubMed]

9. Javaheri S, Barbe F, Campos-Rodriguez F, Dempsey JA, Khayat R, Javaheri S, Malhotra A, Martinez-Garcia MA, Mehra R, Pack Al, Polotsky VY, Redline S, Somers VK. Sleep Apnea: Types, Mechanisms, and Clinical Cardiovascular 
Consequences. J Am Coll Cardiol. 2017 Feb 21;69(7):841-858. [CrossRef] [PubMed]

10. McEvoy RD, Antic NA, Heeley E, Luo Y, Ou Q, Zhang X, Mediano O, Chen R, Drager LF, Liu Z, Chen G, Du B, McArdle N, Mukherjee S, Tripathi M, Billot L, Li Q, Lorenzi-Filho G, Barbe F, Redline S, Wang J, Arima H, Neal B, White DP, Grunstein RR, Zhong N, Anderson CS; SAVE Investigators and Coordinators. CPAP for Prevention of Cardiovascular Events in Obstructive Sleep Apnea. N Engl J Med. 2016 Sep 8;375(10):919-31. [CrossRef] [PubMed].

11. Anonymous. CPAP - Benefits and Health Risk Prevention. AASM. Sleep Education. 2015, Aug. 10. Available at: http://sleepeducation.org/essentials-insleep/cpap/benefits (accessed 10/18/20). 